\title{
Minimally invasive surgery for choledochal cysts: Laparoscopic versus robotic approaches
}

\author{
Jong Hwi Yoon ${ }^{1}$, Ho Kyoung Hwang ${ }^{1,2}$, Woo Jung Lee ${ }^{1,2}$, and Chang Moo Kang ${ }^{1,2}$ \\ ${ }^{1}$ Division of HBP Surgery, Department of Surgery, Yonsei University College of Medicine, \\ ${ }^{2}$ Pancreatobiliary Cancer Center, Yonsei Cancer Center, Severance Hospital, Seoul, Korea
}

\begin{abstract}
Backgrounds/Aims: Minimally invasive surgery is a widely accepted approach in hepatobiliary surgery and choledochal cyst excision has also been performed by minimally invasive methods, including laparoscopic and robotic approaches. However, only a few studies have compared laparoscopic and robotic surgery. Therefore, we performed a comparative study between two groups, including cost aspects. Methods: We retrospectively analyzed minimally invasive choledochal cyst excision at Severance Hospital in Seoul, South Korea from January 2005 to December 2018. A total of 39 patients that underwent minimally invasive choledochal cyst excision were identified. The 23 patients $(58.9 \%)$ and 16 patients $(41.1 \%)$ were enrolled in laparoscopic and robotic approach, respectively. We compared the patient's characteristics, and perioperative outcomes between laparoscopic and robotic surgery groups. Results: A comparative analysis between the two groups showed no differences in preoperative clinical characteristics. There were no significant differences in operative time, estimated blood loss, and postoperative complications, including biliary complication. The preoperative ASA score $(p=0.021)$ and hospital stays $(p=0.011)$ were the only clinical variables that differed between the two groups. All of the variables included in the cost analysis showed statistically significant differences (total hospital charge: $p=0.035$, patient's bill: $p \leq 0.001$, operation: $p=0.002$, anesthesia: $p=0.001$, postoperative management: $p=0.001)$. Conclusions: The overall clinical outcomes between the laparoscopic and robotic approach to choledochal cyst were comparable. The surgical approach should be balanced based on the surgeons' skill, patients' general condition, disease extent, and economic status. (Ann Hepatobiliary Pancreat Surg 2021;25:71-77)
\end{abstract}

Key Words: Choledochal cyst; Laparoscopy; Robotic surgical procedure

\section{INTRODUCTION}

Choledochal cysts are a rare cystic disease in the biliary tract. Most cases develop in children under 10 years of age and there is a higher incidence in the Asian population than in other ethnicities. ${ }^{1}$ In the past, only enteric drainage was performed for choledochal cysts, leading to recurrent cholangitis due to biliary stasis. The malignant potential of choledochal cysts, such as cholangiocarcinoma and gallbladder cancer which have been reported in 5\% to $10 \%$ of patients with choledochal cysts, ${ }^{2}$ is concerning. Therefore, surgical resection of the cyst and cholecystectomy with appropriate reconstruction for biliary drainage using a bilo-enteric anastomosis is typically performed today. ${ }^{3-5}$

Minimally invasive surgery is more widely accepted in hepatobiliary surgery. Choledochal cyst excision has also been performed by minimally invasive methods, including laparoscopic and robotic approaches. ${ }^{6-10}$ Furthermore, several studies have compared clinicopathologic outcomes between laparoscopic and robotic surgeries and have shown the superiority and feasibility of robotic surgery. ${ }^{11,12}$ However, the number of reported studies on minimally invasive choledochal cyst excisions is not sufficient, especially in regard to cost efficiency.

Therefore, we investigated a total of 39 cases of minimally invasive choledochal cyst excision and compared short-term outcomes between laparoscopic and robotic approaches, including cost aspects.

Received: October 5, 2020; Revised: November 6, 2020; Accepted: November 6, 2020

Corresponding author: Chang Moo Kang

Department of Surgery, Yonsei University College of Medicine, Ludlow Faculty Research Building \#203, 250 Seongsan-ro, Seodaemun-gu, Seoul 03722, Korea

Tel: +82-2-2228-2100, Fax: +82-2-2228-2135, E-mail: cmkang@yuhs.ac

Copyright (C) 2021 by The Korean Association of Hepato-Biliary-Pancreatic Surgery

This is an Open Access article distributed under the terms of the Creative Commons Attribution Non-Commercial License (http://creativecommons.org/ licenses/by-nc/4.0) which permits unrestricted non-commercial use, distribution, and reproduction in any medium, provided the original work is properly cited. Annals of Hepato-Biliary-Pancreatic Surgery • pISSN: 2508-5778 - elSSN: 2508-5859 


\section{MATERIALS AND METHODS}

\section{Data collection}

The medical records of the patients who underwent surgery for choledochal cysts in the Severance Hospital in Seoul, South Korea from January 2005 to December 2018 were retrospectively reviewed. Patients who needed combined hepatectomy were excluded. Perioperative clinical parameters such as age, sex, body mass index (BMI), chief complaint, presence of anomalous pancreaticobiliary ductal union (APBDU), Todani classification, American Society of Anesthesiologist (ASA) score, preoperative carcinoembryonic antigen (CEA), Carbohydrate antigen (CA) 19-9, total bilirubin, operation time, estimated blood loss, retrieved lymph nodes, medical cost, hospital stays, types of complication, postoperative intervention and period of surgery were collected. Biliary stricture was defined as follow-up abdomino-pelvic computed tomography (APCT) findings which showed intrahepatic duct dilatation and a need for interventional radiological management, such as percutaneous transhepatic biliary drainage. Biliary leakage was also diagnosed with APCT scans and some cases needed percutaneous drainage. Laboratory tests were also used to diagnose biliary complications.

Preoperative magnetic resonance cholangiopancreatog- raphy and APCT were performed on all included cases to evaluate the clinical stage and type of choledochal cyst. Patients were followed-up on an outpatient basis. APCT and laboratory tests, including for tumor markers were performed within 6 months after surgery to evaluate early and delayed postoperative complications.

\section{Surgical technique}

Brief minimally invasive surgical procedures are showed in Fig. 1. Using a robotic surgical system is preferred for an accurate and gentle anastomosis, because it allows for stable handling and suturing. However, the surgical instruments for excision in robotic surgical systems are limited. Based on the assessment that laparoscopic resection is more appropriate, robotic cases were performed by a hybrid procedure, with the exception of the first few cases. Selection of the surgical approach was determined based on the surgeon's preference and the patient's financial status. A case of robot-assisted excision of choledochal cysts, hepaticojejunostomy, and extracorporeal Roux-en-y anastomosis was reported previously and the detailed surgical technique was described in that report. ${ }^{9}$

\section{Cost analysis}

The total hospital charges were classified into four cate-
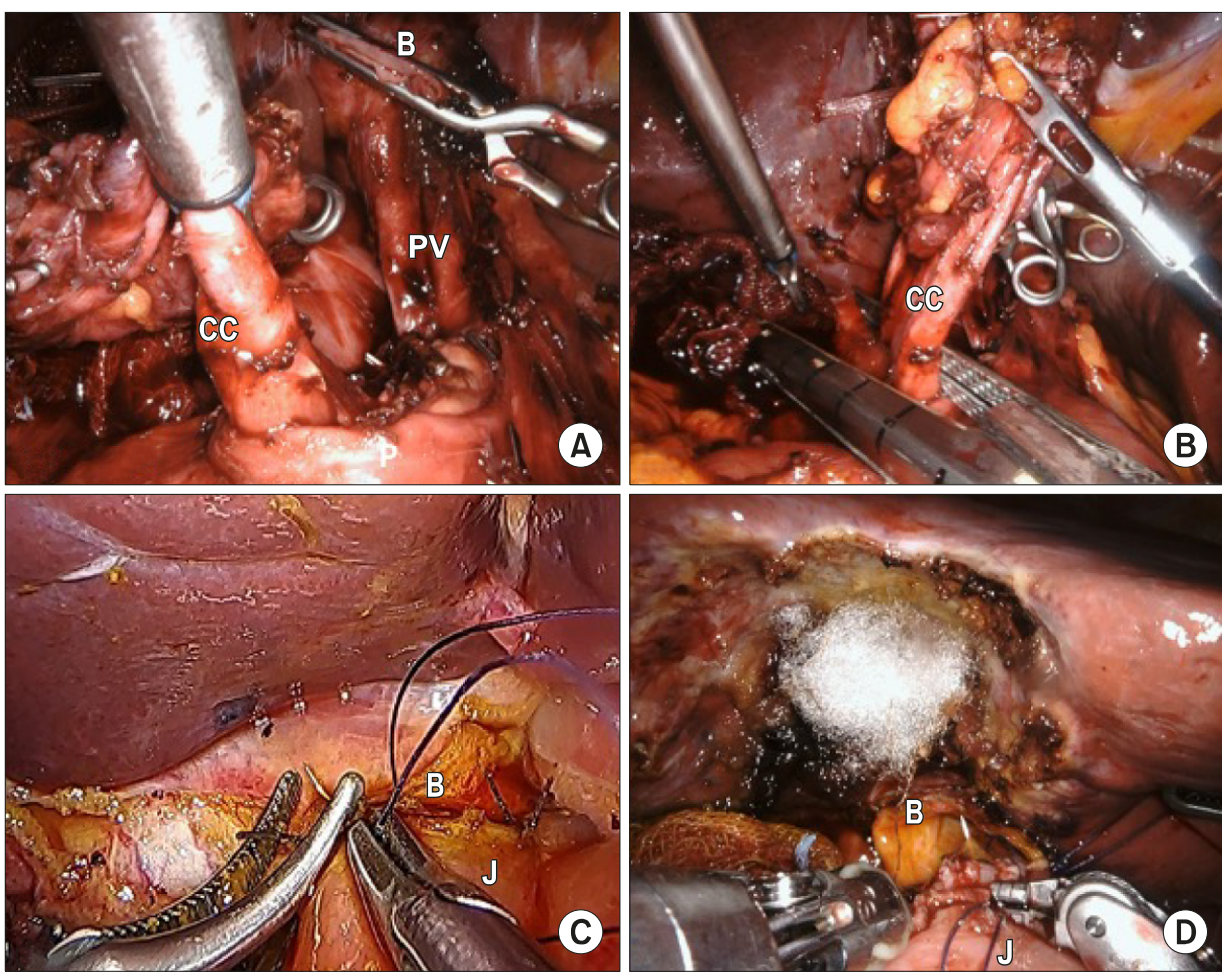

Fig. 1. Minimally invasive approach to treat choledochal cyst. Laparoscopic isolation (A), and resection of choledochal cyst (B). Note subsequent laparoscopic choledochojejunostomy (C) and robotic reconstruction (D). B, bile duct; CC, choledochal cyst; $\mathrm{D}$, duodenum; J, jejunum. 
Table 1. Incidence of surgery over time according to surgical approach

\begin{tabular}{lllrr}
\hline & $2005-2008$ & $2009-2013$ & $2014-2018$ & $p$ \\
\hline Laparoscopic $(\mathrm{n}=23)$ & $1(11.1 \%)$ & $4(40.0 \%)$ & $18(90.0 \%)$ & $<0.001$ \\
Robotic $(\mathrm{n}=16)$ & $8(88.9 \%)$ & $6(60.0 \%)$ & $2(10.0 \%)$ & \\
\hline
\end{tabular}

gories: total hospital charge, patient's bill, operative charge, anesthesia charge, and charges from postoperative management. Considering that the reimbursement of hospital charges is about $80 \%$ by the National Health Insurance Corporation (NHIC), the actual patient's bill was classified separately, and was defined by the sum of $20 \%$ of the insured charge and $100 \%$ the of non-insured charge. The operative charge included the surgery fee and cost of instruments and supplies for the surgery. The anesthesia charge included a fee for anesthesia, medications for induction and maintenance of anesthesia. In some cases, intravenous patient-controlled analgesia was applied and charged as a non-insured anesthesia charge. Charges for postoperative management included any medications for postoperative care, imaging studies for follow-up and surveillance of postoperative complications and laboratory tests. All costs were converted to US dollars based on the exchange rate of May $2019(\$ 1=W 1,197)$.

\section{Statistical analysis}

Continuous variables were analyzed with a student t-test or Mann-Whitney U test in the case of non-normal distribution. Categorical variables were analyzed by chi-square test or Fisher's exact test. Operation time was also analyzed and compared by simple linear regression analysis. The data were analyzed by SPSS (Version 21, IBM, USA).

\section{RESULTS}

\section{Chronological changes in the surgical approach to choledochal cysts}

A total of 39 patients that underwent minimally invasive choledochal cyst excision were identified. The laparoscopic approach was performed in 23 patients (58.9\%), and the robotic approach was performed in 16 patients (41.1\%). In the early period of applying the minimally invasive approach to choledochal cysts, robotic surgery was performed more frequently than laparoscopic surgery. Over time, with the experiences of laparoscopic surgery
Table 2. Preoperative clinical characteristics

\begin{tabular}{|c|c|c|c|}
\hline & $\begin{array}{l}\text { Laparoscopic } \\
\qquad(\mathrm{n}=23)\end{array}$ & $\begin{array}{l}\text { Robotic } \\
(\mathrm{n}=16)\end{array}$ & $p$ \\
\hline Sex & & & 0.674 \\
\hline Male & $3(13.0 \%)$ & $3(18.7 \%)$ & \\
\hline Female & $20(87.0 \%)$ & $13(81.3 \%)$ & \\
\hline Age (years) & $34.3 \pm 11.2$ & $37.0 \pm 10.7$ & 0.462 \\
\hline BMI $\left(\mathrm{kg} / \mathrm{m}^{2}\right)$ & $23.0 \pm 3.0$ & $21.4 \pm 2.4$ & 0.098 \\
\hline Chief complaint & & & 0.987 \\
\hline No & $13(56.5 \%)$ & $9(56.3 \%)$ & \\
\hline Pain & $10(43.5 \%)$ & $7(43.7 \%)$ & \\
\hline Past medical history & & & 0.100 \\
\hline None & $22(95.7 \%)$ & $13(81.3 \%)$ & \\
\hline Diabetes & $0(0.0 \%)$ & $2(12.5 \%)$ & \\
\hline Hepatitis & $0(0.0 \%)$ & $1(6.3 \%)$ & \\
\hline Multiple combined & $1(4.3 \%)$ & $0(0.0 \%)$ & \\
\hline ASA score & & & 0.021 \\
\hline 1 & $15(65.2 \%)$ & $16(100.0 \%)$ & \\
\hline 2 & $6(26.1 \%)$ & $0(0.0 \%)$ & \\
\hline 3 & $2(8.7 \%)$ & $0(0.0 \%)$ & \\
\hline Todani classification & & & 0.398 \\
\hline I & $22(95.7 \%)$ & $16(100.0 \%)$ & \\
\hline II & $1(4.3 \%)$ & $0(0.0 \%)$ & \\
\hline $\begin{array}{l}\text { Diameter of bile duct } \\
(\mathrm{mm})\end{array}$ & $9.8 \pm 1.9$ & $11.5 \pm 4.3$ & 0.099 \\
\hline $\begin{array}{l}\text { Preoperative CEA } \\
\text { level }(\mathrm{ng} / \mathrm{ml})\end{array}$ & $1.3 \pm 1.7$ & $1.4 \pm 1.1$ & 0.363 \\
\hline $\begin{array}{l}\text { Preoperative CA19-9 } \\
(\mathrm{U} / \mathrm{ml})\end{array}$ & $11.2 \pm 13.3$ & $13.4 \pm 12.0$ & 0.358 \\
\hline $\begin{array}{l}\text { Preoperative total } \\
\text { bilirubin }(\mathrm{mg} / \mathrm{dl})\end{array}$ & $0.6 \pm 0.3$ & $0.7 \pm 0.4$ & 0.366 \\
\hline
\end{tabular}

increasing, the incidence of laparoscopic surgery increased beyond robotic surgery (Table 1).

\section{Preoperative clinical characteristics}

The general characteristics of patients are presented in Table 2. There were no significant differences in sex, age, chief complaint, and past medical history. The preoperative BMI was also similar between the two groups (23.0土 3.0 vs. $21.4 \pm 2.4, p=0.098$ ).

The preoperative clinical variables are shown in Table 2. There were no significant general clinical differences between the two groups. According to Todani classification, Type I was most common in both groups and only 
1 case belonging to the robotic group was classified as type II. Diameter of bile duct measured at upper resection margin was similar between two groups (mm, $9.8 \pm 1.9$ vs. $11.5 \pm 4.3, p=0.099)$. The mean preoperative CEA (ng/ml, $1.3 \pm 1.7$ vs. $1.4 \pm 1.1, p=0.363)$, CA $19-9(\mathrm{U} / \mathrm{ml}, 11.2 \pm 13.3$ vs. $13.4 \pm 12.0, p=0.358)$ and total bilirubin $(\mathrm{mg} / \mathrm{dl}, 0.6 \pm 0.3$ vs. $0.7 \pm 0.4, p=0.366$ ) were also similar between the two groups. The ASA score was the only variable that showed a statistically significant difference in the preoperative findings $(p=0.021)$.

\section{Intraoperative and postoperative outcome}

Several intraoperative findings are presented in Table 3. No significant difference in the average operation time was observed between the two groups $(333.6 \pm 60.9$ vs. 362.9 $\pm 86.6, p=0.221)$. The mean estimated blood loss (ml) was higher in the robotic surgery group but not significantly different compared to the laparoscopic group (128.3 \pm 159.1 vs. $186.9 \pm 214.7, p=0.746)$. The number of retrieved lymph nodes is minimal in both groups $(1.2 \pm 2.6$ vs. $0.1 \pm 0.3, p=0.114$ ). Some perioperative findings showing postoperative outcomes are presented in Table 3.

Table 3. Intraoperative and postoperative outcomes

\begin{tabular}{lccc}
\hline & $\begin{array}{c}\text { Laparoscopic } \\
(\mathrm{n}=23)\end{array}$ & $\begin{array}{c}\text { Robotic } \\
(\mathrm{n}=16)\end{array}$ & $p$ \\
\hline $\begin{array}{l}\text { Retrieved lymph node } \\
\text { Complications }\end{array}$ & $1.2 \pm 2.6$ & $0.1 \pm 0.3$ & 0.114 \\
$\quad$ None & $16(69.6 \%)$ & $8(50.0 \%)$ & 0.069 \\
$\quad$ Biliary complication & $6(26.1 \%)$ & $7(43.7 \%)$ & \\
$\quad$ Roux limb & $1(4.3 \%)$ & $0(0.0 \%)$ & \\
$\quad$ obstruction & & & \\
$\quad \begin{array}{l}\text { Port site hernia } \\
\text { Postoperative interventions }\end{array}$ & $0(0.0 \%)$ & $1(6.3 \%)$ & \\
$\quad$ None & $20(87.0 \%)$ & $13(81.3 \%)$ & \\
PTBD & $2(8.7 \%)$ & $3(18.8 \%)$ & \\
Pigtail insertion & $1(4.3 \%)$ & $0(0.0 \%)$ & \\
\hline
\end{tabular}

Table 4. Comparison of biliary complications

\begin{tabular}{lccc}
\hline $\begin{array}{c}\text { Minimally } \\
\text { invasive } \\
\text { approach }\end{array}$ & $\begin{array}{c}\text { Laparoscopic } \\
(\mathrm{n}=23)\end{array}$ & $\begin{array}{c}\text { Robotic } \\
(\mathrm{n}=16)\end{array}$ & $p$ \\
\hline $\begin{array}{l}\text { Bile leakage } \\
\text { No }\end{array}$ & $21(91.3 \%)$ & $11(68.8 \%)$ & 0.101 \\
Yes & $2(8.7 \%)$ & $5(31.3 \%)$ & \\
Biliary stricture & $21(91.3 \%)$ & $13(81.3 \%)$ & \\
No & $2(8.7 \%)$ & $3(18.8 \%)$ & \\
Yes & & & \\
\hline
\end{tabular}

Hospital stays (days) were significantly longer in the robotic surgery group than in the laparoscopic surgery group ( $11.4 \pm 6.3$ vs. $14.7 \pm 5.6, p=0.011)$. The incidence of postoperative complications was higher in the robotic surgery group. Table 4 shows biliary complication between two groups. Biliary leakage was observed more frequently in the robotic surgery group than in the laparoscopic surgery group, but the finding was not statistically significant ( $8.7 \%$ vs. $31.3 \%, p=0.101)$. Biliary stricture was also more common in the robotic surgery group $(8.7 \%$ vs. $18.8 \%$, $p=0.631$ ). Biliary stricture free probability is showed in Fig. 2 and there is no statistical difference.

\section{Cost analysis}

The total hospital charge was higher in the robotic group (\$6,568 $\pm 1,047$ vs. $\$ 7,331 \pm 720, p=0.035$ ) (Table 5). The difference in the actual patient's bill was also remarkably higher in the robotic group $(\$ 2,626 \pm 632$ vs. $\$ 6,578 \pm$ $1,081, p<0.001)$. The anesthesia charge was higher too in the robotic group $(\$ 612 \pm 138$ vs. $\$ 788 \pm 154, p=0.001)$. But the charge from postoperative management was higher in the laparoscopic group compared with the robotic

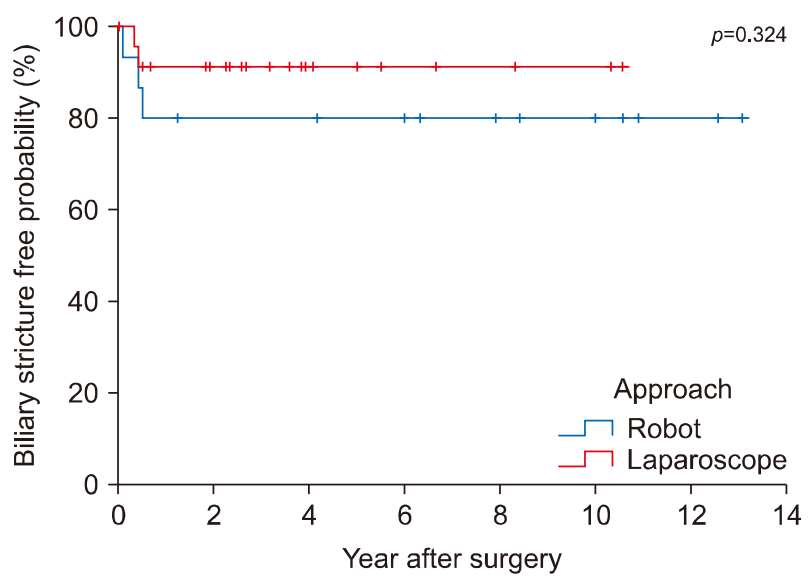

Fig. 2. Time-dependent biliary stricture-free probability.

Table 5. Comparison of hospital charges (US\$)

\begin{tabular}{lccr}
\hline & $\begin{array}{c}\text { Laparoscopic } \\
(\mathrm{n}=23)\end{array}$ & $\begin{array}{c}\text { Robotic } \\
(\mathrm{n}=16)\end{array}$ & $p$ \\
\hline Total hospital charge & $6,568 \pm 1,047$ & $7,331 \pm 720$ & 0.035 \\
Patient's bill & $2,626 \pm 632$ & $6,578 \pm 1,081$ & $<0.001$ \\
Operation & $4810 \pm 954$ & $5,781 \pm 845$ & 0.002 \\
Anesthesia & $612 \pm 138$ & $788 \pm 154$ & 0.001 \\
Postoperative & $1,098 \pm 260$ & $716 \pm 264$ & 0.001 \\
$\quad$ & & & \\
\hline
\end{tabular}


group $(\$ 1,098 \pm 260$ vs. $\$ 716 \pm 264, p=0.001)$.

\section{DISCUSSION}

As minimally invasive techniques became popular in oncologic surgery, the cases of minimally invasive choledochal cyst excision increased since the approach was first reported in 1995 by Farello et al. ${ }^{13}$ Our institution has been performing minimally invasive choledochal cyst excision since 2005 and a total of 39 cases which consisted of 23 laparoscopic cases and 16 robotic cases, have been performed up until December 2018.

There was no significant difference in the patient's characteristics. Perioperative outcomes were also similar, except for hospital stays which was longer in the robotic group (11.4 \pm 6.3 vs. $14.7 \pm 5.6, p=0.011)$. Most patients with robotic surgery had private insurance, which led to a delay in discharge from the hospital, and this factor seems to be associated with longer hospital stays. In addition, a higher rate of complications in the robotic surgery group required additional time in postoperative management. However, when referring to other studies, variables like postoperative complications and data for comparing functional recovery rather than length of hospital stay can be more appropriate to evaluate efficacy of minimally invasive surgery. ${ }^{14-16}$

As mentioned before, the rate of biliary complications for containing bile leakage and biliary stricture were higher in the robotic surgery group. This result showed contradictory view from other papers dealing with minimally invasive choledochal cyst excision. ${ }^{11,12}$ But there was possibility of bias in different biliary stricture rate between two groups. It might be associated with surgeon's learning curve and observation period. Considering that some time (median 131 month) is needed for development of biliary stricture, the minimally invasive surgery for choledochal cyst excision was almost done with robotic approach in early period of time. Therefore, higher prevalence of biliary stricture in robotic surgery group was also explained by other factors as mentioned above. Further follow up study is mandatory.

The total hospital charge was higher in the robotic group compared to the laparoscopic group, especially regard to operation charge. Because the cost for robotic surgery is not included in the insurance charge, the cost for robotic surgery is not reimbursed by the NHIS in South Korea, therefore, the patient's burden for the hospital charge was significantly higher in the robotic group. So, the presence of private insurance affected the patient's choice of surgical methods, laparoscopic or robotic. Even though longer hospital stays were observed in the robotic surgery group, the cost from postoperative management was higher in the laparoscopic surgery group. This is likely attributable to the increase in the amount of routinely used drugs, combined with the increase in the rate of laparoscopic surgery over time.

Robotic surgery was introduced in the late 1990s and was initially confined to several medical areas, including urology and gynecology. As refinement of the technology, such as better image quality, and reduced charges for surgery, robotic surgery has expanded into general surgery fields such as hepatobiliary, colorectal, endocrine surgery and even breast surgery. ${ }^{17-20}$ Robotic surgery has been developed to overcome disadvantages and limitations of laparoscopic surgery such as limited degree of motion, comprised dexterity, the fulcrum effect and two-dimensional visualization. Despite the advantages of robotic surgery, compared with laparoscopic surgery, there are several disadvantages associated with robotic surgery. The high cost of the operation and set up is a major factor that prevent surgeons from choosing robotic surgery. ${ }^{21,22}$ In terms of oncologic safety, there is limited supporting clinical evidence, therefore factors such as a shortage of long-term clinical outcomes is a concern for robotic surgery. The da Vinci ${ }^{\circledR}$ Surgical System which is the most widely used robot surgical system in our institution is comprised of three components: The Surgeon's console, Patient's cart, and the Vision cart. Not only does it require a specific amount of space, but the system also requires skilled extra staff to assist with docking the system to the patient. Therefore, an additional charge and time were needed to satisfy all these factors.

At our institution, minimally invasive choledochal cyst excision was initially performed with the robotic approach. Based on those experiences, laparoscopic surgical skills were improved and other hepatobiliary surgeries such as hepatectomy and pancreatectomy have been performed more recently with the laparoscopy. As a result, in consideration of the general conditions and economic status of patients, performance of laparoscopic choledochal cyst ex- 
cision also increased, rather than unconditionally adopting robotic surgery.

Our study has several limitations. The first is that some surgical procedures in the same group were not performed in the same way. For example, among 23 cases of laparoscopic surgery, 16 cases were performed for the Roux-en-y hepaticojejunostomy by the intracorporeal method but in the remaining 7 cases, they were performed extracorporeally. The robotic surgery group also did not have the same Roux-en-y hepaticojejunostomy method (3 intracorporeally vs. 13 extracorporeally). This is associated with the selection of the surgical approach (hybrid or total robotic approach).

The second limitation is that this study was designed retrospectively; thus, several medical records, such as detailed postoperative complications related to this study could not be verified. The third is that there was a shortage of cases because of the single institution in the study. Choledochal cysts are more commonly diagnosed in children and more of the surgeries were actually performed in children. ${ }^{1}$ However, the youngest person in this study was 15 years old and most people were over 20 years old.

In conclusion, the overall statistical outcomes between laparoscopic and robotic choledochal cyst excision approaches were comparable, and the selection of surgical method should be decided in consideration of variety factors including const aspect.

\section{CONFLICT OF INTEREST}

The authors have no potential conflicts of interest to disclose.

\section{ORCID}

Jong Hwi Yoon: https://orcid.org/0000-0002-2917-2274

Ho Kyoung Hwang: https://orcid.org/0000-0003-4064-7776

Woo Jung Lee: https://orcid.org/0000-0001-9273-261X

Chang Moo Kang: https://orcid.org/0000-0002-5382-4658

\section{AUTHOR CONTRIBUTIONS}

Conceptualization: JHY, HKH, WJL, CMK. Data curation: HKH, WJL, CMK. Formal analysis: JHY, CMK. Methodology: JHY, HKH, WJL, CMK. Project admin- istration: JHY, HKH, WJL, CMK. Writing - original draft: JHY. Writing - review \& editing: JHY, HKH, WJL, CMK.

\section{REFERENCES}

1. Soares KC, Kim Y, Spolverato G, Maithel S, Bauer TW, Marques H, et al. Presentation and clinical outcomes of choledochal cysts in children and adults: a multi-institutional analysis. JAMA Surg 2015;150:577-584.

2. Jan YY, Chen HM, Chen MF. Malignancy in choledochal cysts. Hepatogastroenterology 2002;49:100-103.

3. Lipsett PA, Pitt HA. Surgical treatment of choledochal cysts. J Hepatobiliary Pancreat Surg 2003;10:352-359.

4. Todani T, Watanabe Y, Narusue M, Tabuchi K, Okajima K. Congenital bile duct cysts: classification, operative procedures, and review of thirty-seven cases including cancer arising from choledochal cyst. Am J Surg 1977;134:263-269.

5. Moreno González E, García García I, Hidalgo Pascual M, Calleja Kempin J, García Blanch G, Gómez Gutiérrez M, et al. Choledochal cyst resection and reconstruction by biliary-jejuno-duodenal diversion. World J Surg 1989;13:232-237; discussion 237.

6. Tanaka M, Shimizu S, Mizumoto K, Yokohata K, Chijiiwa K, Yamaguchi K, et al. Laparoscopically assisted resection of choledochal cyst and Roux-en-Y reconstruction. Surg Endosc 2001;15: 545-552.

7. Li L, Feng W, Jing-Bo F, Qi-Zhi Y, Gang L, Liu-Ming H, et al. Laparoscopic-assisted total cyst excision of choledochal cyst and Roux-en-Y hepatoenterostomy. J Pediatr Surg 2004;39:16631666.

8. Ure BM, Schier F, Schmidt AI, Nustede R, Petersen C, Jesch NK. Laparoscopic resection of congenital choledochal cyst, choledochojejunostomy, and extraabdominal Roux-en-Y anastomosis. Surg Endosc 2005;19:1055-1057.

9. Kang CM, Chi HS, Kim JY, Choi GH, Kim KS, Choi JS, et al. A case of robot-assisted excision of choledochal cyst, hepaticojejunostomy, and extracorporeal Roux-en-y anastomosis using the da Vinci surgical system. Surg Laparosc Endosc Percutan Tech 2007; 17:538-541.

10. Woo R, Le D, Albanese CT, Kim SS. Robot-assisted laparoscopic resection of a type I choledochal cyst in a child. J Laparoendosc Adv Surg Tech A 2006;16:179-183.

11. Lee H, Kwon W, Han Y, Kim JR, Kim SW, Jang JY. Comparison of surgical outcomes of intracorporeal hepaticojejunostomy in the excision of choledochal cysts using laparoscopic versus robot techniques. Ann Surg Treat Res 2018;94:190-195.

12. Han JH, Lee JH, Hwang DW, Song KB, Shin SH, Kwon JW, et al. Robot resection of a choledochal cyst with Roux-en-y hepaticojejunostomy in adults: initial experiences with 22 cases and a comparison with laparoscopic approaches. Ann Hepatobiliary Pancreat Surg 2018;22:359-366.

13. Farello GA, Cerofolini A, Rebonato M, Bergamaschi G, Ferrari C, Chiappetta A. Congenital choledochal cyst: video-guided laparoscopic treatment. Surg Laparosc Endosc 1995;5:354-358.

14. Porpiglia F, Morra I, Lucci Chiarissi M, Manfredi M, Mele F, Grande S, et al. Randomised controlled trial comparing laparoscopic and robot-assisted radical prostatectomy. Eur Urol 2013;63: 606-614.

15. Lee SY, Park YM, Byeon HK, Choi EC, Kim SH. Comparison of oncologic and functional outcomes after transoral robotic lateral oropharyngectomy versus conventional surgery for T1 to T3 tonsillar cancer. Head Neck 2014;36:1138-1145.

16. Kim JH, Park YH, Kim YJ, Kang SH, Byun SS, Kwak C, et 
al. Perioperative and long-term renal functional outcomes of robotic versus laparoscopic partial nephrectomy: a multicenter matched-pair comparison. World J Urol 2015;33:1579-1584.

17. Kang SW, Jeong JJ, Yun JS, Sung TY, Lee SC, Lee YS, et al. Robot-assisted endoscopic surgery for thyroid cancer: experience with the first 100 patients. Surg Endosc 2009;23:2399-2406.

18. Lee KE, Rao J, Youn YK. Endoscopic thyroidectomy with the da Vinci robot system using the bilateral axillary breast approach (BABA) technique: our initial experience. Surg Laparosc Endosc Percutan Tech 2009;19:e71-e75.

19. Spinoglio G, Summa M, Priora F, Quarati R, Testa S. Robotic colorectal surgery: first 50 cases experience. Dis Colon Rectum 2008;51:1627-1632.

20. Toesca A, Peradze N, Galimberti V, Manconi A, Intra M, Gentilini $\mathrm{O}$, et al. Robotic nipple-sparing mastectomy and immediate breast reconstruction with implant: first report of surgical technique. Ann Surg 2017;266:e28-e30.

21. Lanfranco AR, Castellanos AE, Desai JP, Meyers WC. Robotic surgery: a current perspective. Ann Surg 2004;239:14-21.

22. Jung M, Morel P, Buehler L, Buchs NC, Hagen ME. Robotic general surgery: current practice, evidence, and perspective. Langenbecks Arch Surg 2015;400:283-292. 